\title{
The Common Barriers and Facilitators for a Healthcare Organization Becoming a High Reliability Organization
}

\author{
Elina Karalis, Gaery Barbery
}

Health Services Management, School of Medicine, Griffith University, Brisbane Queensland 4101, Australia

Correspondence: elina.karalis@griffithuni.edu.au

\section{ABSTRACT}

Background: Implementing high reliability organization principles can enhance quality and safety in healthcare. Evidence-based instructions on how to effectively change the organizational culture in healthcare setting are required.

Objectives: A systematic review investigating methods, facilitators, and barriers to assist healthcare organizations in becoming a high reliability organization.

Method: Literature searches were performed in PubMed, MEDLINE, CINAHL-Complete, EMBASE, and Scopus for articles published between January 2012 and October 2017. The included articles were case reports, case studies, and protocol development studies on implementing high reliability organization principles. The articles were appraised using a modified Critical Appraisal Skills Programme tool. Thematic synthesis was conducted using manual coding.

\section{INTRODUCTION}

Improving patient safety and quality of care is a high priority within the healthcare organizations. However, there is a long way to go. Medication errors cost $\$ 1.2$ billion annually to the Australian hospital system. [1] Furthermore, it has been estimated that one third of deaths in USA are due to medical
Results: Of the 14 eligible articles nine were case studies, four were case reports, and one was a framework development report. The study populations varied from whole healthcare systems to a single department of a hospital. The most common methods were supportive leadership, staff education, and analysing the safety events and sharing the knowledge. Cost was one of the barriers. Remuneration came in reduction of safety events and costs avoided.

Conclusion Implementing high reliability organization principles in healthcare settings is slow and challenging, but doing so improves quality, resilience, and safety, thus increasing productivity.

Keywords: high reliability organization, healthcare, quality improvement, patient safety, medical error.

errors and [2] about $40 \%$ of patient injuries in hospitals are preventable. [3]

Some organizations manage risks better than others. A distinctive characteristic to all high reliability organizations (HRO) is that they operate in uncertain, high-risk environments 
without serious accidents. [4] Furthermore, they prioritize safety over other performance pressures and create an environment in which potential problems are anticipated, detected early, and responded to early enough to prevent serious consequences. [4]

The five principles of HROs' are: preoccupation with failure, reluctance to simplify, sensitivity to operations, commitment to resilience, and deference to expertise. [5]

Organizations preoccupied with failure understand that even small errors can be clues of bigger failures in the system. Thus, they encourage people to ask questions and report errors or mistakes. [6] Furthermore, they recognize the expectations and situations where practices are performed may fail. [7] These situations include recent changes in supervision, delegation of tasks without follow-up, shortage of staff, and lack of proper communication between the staff. [8]

HROs resist simplifying explanations to problems. Instead, they develop more complete, detailed, and wider view of the situation. [9] HROs are sensitive to operations by supporting the routine work in front line, and by viewing near-misses as opportunities to better understand what went wrong and how it could be prevented in the future. [10-12] HROs are committed to be resilient in unexpected situations. [13] They can preserve functioning despite the presence of adversity, they recover from untoward events, and learn from previous unexpected events. [14, 15] HROs defer to expertise when an accident has happened. That means the authority migrates to the people with most knowledge and experience instead of those highest in hierarchy. [16-18]
HROs are able to achieve the balance between safety and production. HROs and healthcare organizations both operate in uncertain, highrisk environments. Adapting HRO principles in healthcare can help healthcare organization to improve their safety and quality performance. [19] The amount of published reports of applying HRO principles in healthcare is slowly increasing but to our knowledge, there is no current systematic review of the common barriers and facilitators for HRO principles in healthcare.

The aim of this systematic literature review is to provide a knowledge synthesis of HRO processes in healthcare and thus help the leaders in healthcare organizations to decide whether to pursue HRO status. The specific objectives for this literature review are 1) to discover the means to achieve HRO status, 2) to detected possible challenges, and 3 ) to evaluate the long-term benefits a health care organization can gain by achieving and maintaining the HRO status. The conclusions in this systematic literature review are based on 14 peer-reviewed journal articles published during the last five years.

\section{METHODS}

The systematic literature review focused on identifying common barriers and facilitators of healthcare organizations successfully transitioning to a high reliability healthcare organization by addressing the following questions:

1. How can a healthcare organization achieve a HRO status?

2. What are the long-term benefits of maintaining HRO status? 


\section{Search strategy}

A PRISMA systematic literature review framework was used to increase the transparency and reliability of the review. [20] The literature search was conducted in PubMed, MEDLINE, CINAHL-Complete, Embase and Scopus databases in order to uncover medical, international biomedical, and management literature. The search was conducted between 4 November 2017 and 6 November 2017. PICOS framework was used for developing focused literature search strategies. PICOS stands for population, interest, comparison, outcome, and study design. [21] In this case, population was healthcare organizations. Interest was implementing high reliability concept and comparison was the situation before the change. Relevant outcomes were to understand the approaches, challenges and benefits health care organizations have had while implementing high reliability concepts.

The search terms included: HIGH + RELIABILITY + ORGANIZATION, HIGH + RELIABILITY + ORGANIZATIONS. Where possible, the exclusion criteria were used for limiting the search in databases. To include as many relevant articles as possible, further resources were detected by scanning bibliographies of matching articles and by using "similar articles" function in PubMed and "related documents" function in Scopus. The journal articles found during searching were stored and organised in Endnote $\mathrm{X} 8$ software (Clarivate Analytics, USA).
After removing the duplicate articles, titles and abstracts of studies were screened for potential eligibility. The articles that met the inclusion criteria were selected and entered to the final analysis. Full texts of potentially eligible studies were retrieved for final analysis in which the articles were assessed against the inclusion and exclusion criteria. The studies rejected from final analysis were not clearly relevant to the subject of this review or were not accessible online.

\section{Eligibility criteria}

The literature review focused on the key requirements for successful transition process and the long-term influences. Thus, the included articles are case reports, case studies, and a protocol development study. Expert opinions and comments were excluded as well as editorials because of their low quality of evidence. For convenience, articles had to be published in English and be available in electronic format. Other formats and languages were excluded. Only peer-reviewed journals were included because they have a degree of control and credibility. To ensure currency, the review focused on literature produced within the last five years (between 1 January 2012 and 31 October 2017). Articles had to focus on implementing the HRO principles in healthcare. (Table 1) 
Table 1. Inclusion and Exclusion criteria applied in the review.

\begin{tabular}{|c|c|c|}
\hline Criteria & Inclusion & Exclusion \\
\hline Population & $\begin{array}{l}\text { Healthcare } \\
\text { organization }\end{array}$ & $\begin{array}{l}\text { Organizations } \\
\text { outside healthcare }\end{array}$ \\
\hline Interest & $\begin{array}{l}\text { High reliability } \\
\text { organization } \\
\text { concept }\end{array}$ & $\begin{array}{l}\text { Not related to high } \\
\text { reliability } \\
\text { organization } \\
\text { concept }\end{array}$ \\
\hline Study design & $\begin{array}{l}\text { Systematic } \\
\text { literature review }\end{array}$ & $\begin{array}{l}\text { Expert opinion } \\
\text { Expert comment } \\
\text { Literature review }\end{array}$ \\
\hline & $\begin{array}{l}\text { Case report } \\
\text { Case study }\end{array}$ & \\
\hline & $\begin{array}{l}\text { Development of } \\
\text { protocol }\end{array}$ & \\
\hline $\begin{array}{l}\text { Publishing } \\
\text { date }\end{array}$ & $\begin{array}{l}1.1 .2012- \\
30.11 .2017\end{array}$ & Before 1.1.2012 \\
\hline Language & English & Non-English \\
\hline Availability & $\begin{array}{l}\text { Full text } \\
\text { available online }\end{array}$ & $\begin{array}{l}\text { Full text not } \\
\text { available online }\end{array}$ \\
\hline
\end{tabular}

\section{Data extraction and quality assessment}

The following data was abstracted from the articles; title, author, year, characteristics and location of the organization, study design, type of intervention, outcome measures and their definition according to individual studies, follow-up time, the author(s) conclusions, and study limitations. (Table 2 and Table 3 )

The quality of the included studies was evaluated by using a modified CASP cohort study checklist (Critical Appraisal Skills Programme, United Kingdom). [22] This evaluating tool was chosen because most of the selected articles are observational cohort studies and this tool is easy to use. (Table 3)

\section{Synthesis of results}

This systematic literature review used thematic synthesis to conceptualise the collected information of the included articles because the original articles did not address the research questions directly. In thematic synthesis, after data extraction, the data is coded to descriptive themes and finally, analytical themes according the study questions are developed. [23] Thematic synthesis was conducted using manual coding whereby the selected papers were read line by line and coded into themes. 
Table 2. Characteristics of the included articles.

\begin{tabular}{|c|c|c|c|c|c|}
\hline $\begin{array}{l}\text { Reference } \\
\text { number }\end{array}$ & Study & Study design & $\begin{array}{l}\text { Follow- } \\
\text { up time }\end{array}$ & Country & Population \\
\hline 33 & $\begin{array}{l}\text { Aboumatar } \\
\text { et al., } 2017\end{array}$ & Case report & 9 years & USA & 1 academic medical centre \\
\hline 28 & $\begin{array}{l}\text { Brilli et al., } \\
2013\end{array}$ & $\begin{array}{l}\text { Quasi-experimental time } \\
\text { series }\end{array}$ & 3 years & USA & 1 Urban Hospital \\
\hline 37 & $\begin{array}{l}\text { Chassin \& } \\
\text { Loeb, } 2013\end{array}$ & $\begin{array}{l}\text { Iterative testing to } \\
\text { develop a framework }\end{array}$ & $\mathrm{n} / \mathrm{a}$ & USA & Hospital leaders \\
\hline 29 & $\begin{array}{l}\text { Hales et al., } \\
2012\end{array}$ & $\begin{array}{l}\text { Participatory action } \\
\text { research using } \\
\text { prevention-appraisal- } \\
\text { failure method }\end{array}$ & 1 year & USA & 5 intensive care units in 1 hospital \\
\hline 35 & $\begin{array}{l}\text { Hendrich \& } \\
\text { Haydar, } \\
2017\end{array}$ & Case report & 6 years & USA & 1 healthcare system in different states \\
\hline 32 & $\begin{array}{l}\text { Hilliard et } \\
\text { al., } 2012\end{array}$ & Case study & 3 years & USA & 1 hospital \\
\hline 24 & $\begin{array}{l}\text { King et al., } \\
2017\end{array}$ & Case study & 1 year & USA & $\begin{array}{l}54 \text { different military healthcare } \\
\text { providers and hospitals }\end{array}$ \\
\hline 30 & $\begin{array}{l}\text { Lyman et } \\
\text { al., } 2017\end{array}$ & $\begin{array}{l}\text { Participatory action } \\
\text { research using learning } \\
\text { history method }\end{array}$ & $\mathrm{n} / \mathrm{a}$ & USA & 1 intensive care unit \\
\hline 25 & $\begin{array}{l}\text { Lyren et } \\
\text { al., } 2016\end{array}$ & Case study & 3 years & USA & 6 tertiary care hospitals \\
\hline 31 & $\begin{array}{l}\text { Muething } \\
\text { et al., } 2012\end{array}$ & Case study & 4 years & USA & 1 urban hospital \\
\hline 27 & $\begin{array}{l}\text { Peterson et } \\
\text { al., } 2012\end{array}$ & Case study & 1 year & USA & 1 hospital \\
\hline 34 & $\begin{array}{l}\text { Pronovost } \\
\text { et al., } 2015\end{array}$ & Case report & 3 years & USA & $\begin{array}{l}\text { A } 40 \text {-site primary care practice, } 8 \\
\text { ambulatory surgery centres, } 2 \text { home } \\
\text { healthcare companies, an insurance } \\
\text { company, and an international health } \\
\text { company that manages over } 14 \\
\text { hospitals around the world }\end{array}$ \\
\hline 36 & $\begin{array}{l}\text { Saunders \& } \\
\text { Brennan, } \\
2017\end{array}$ & Case report & 9 years & USA & 11 hospitals \\
\hline 26 & $\begin{array}{l}\text { Woodhouse } \\
\text { et al., } 2016\end{array}$ & Case study & 5 years & USA & $\begin{array}{l}\text { Radiation oncology department at a } \\
\text { university hospital }\end{array}$ \\
\hline
\end{tabular}




\section{Results of the literature review}

The initial literature searches generated 153 journal articles. After removing duplications, 150 articles remained. These articles were screened by abstract and title, reducing the list to 19 articles. After applying inclusion/exclusion criteria to the full text of these articles, the number of articles in the final literature review was 14. The PRISMA flow diagram guided this process. [20] (Figure 1.)

All the included articles were from the United States. Nine articles were case studies, [24-32] four articles were case reports [33-36], and one article was a framework development report. [37] The study population varied from whole healthcare systems covering several hospitals $[24,34,36]$ to a single department of a hospital. [26, 30] The follow-up time varied between one and nine years. (Table 2 ) None of the included articles fulfilled all the modified CASP checklist criteria. Most of the articles demonstrated deficits in identifying confounders and considering them in the study design. (Table 3)

Figure 1. Prisma flow diagram.
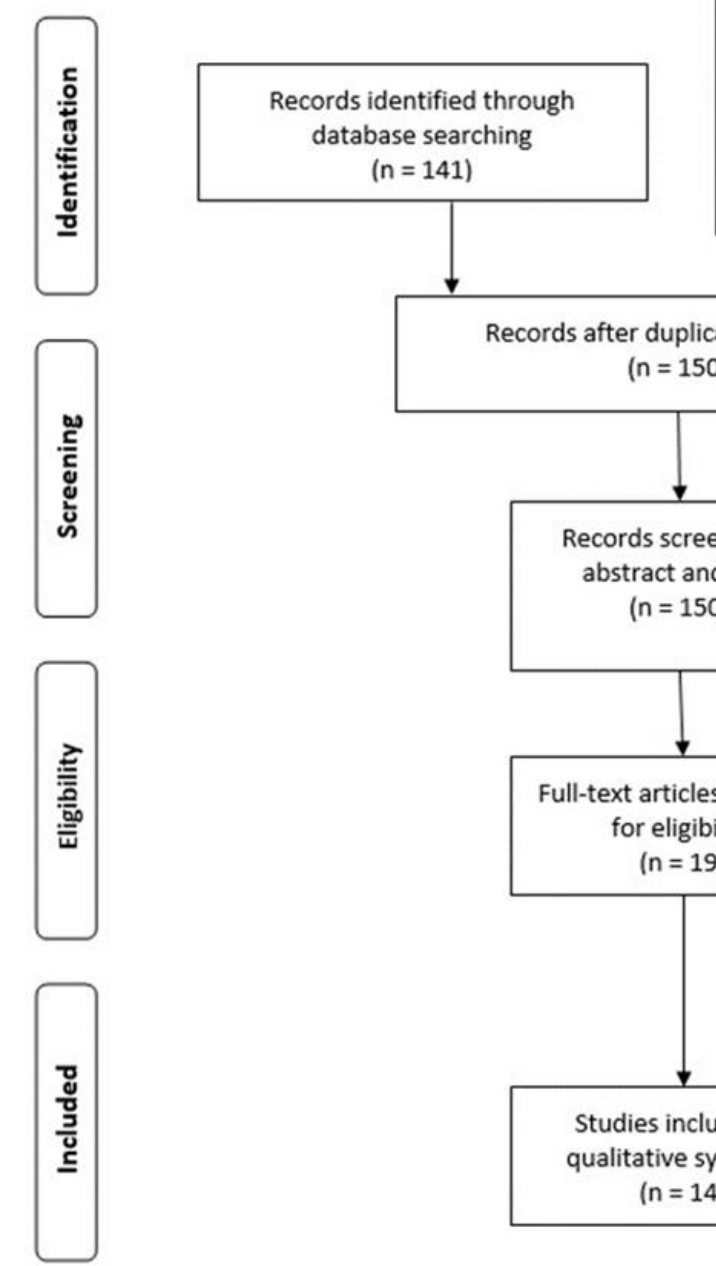

Additional records identified through other sources (bibliographies of matching articles and by using "similar articles" function in PubMed and "related documents" function in Scopus

$(\mathrm{n}=12)$
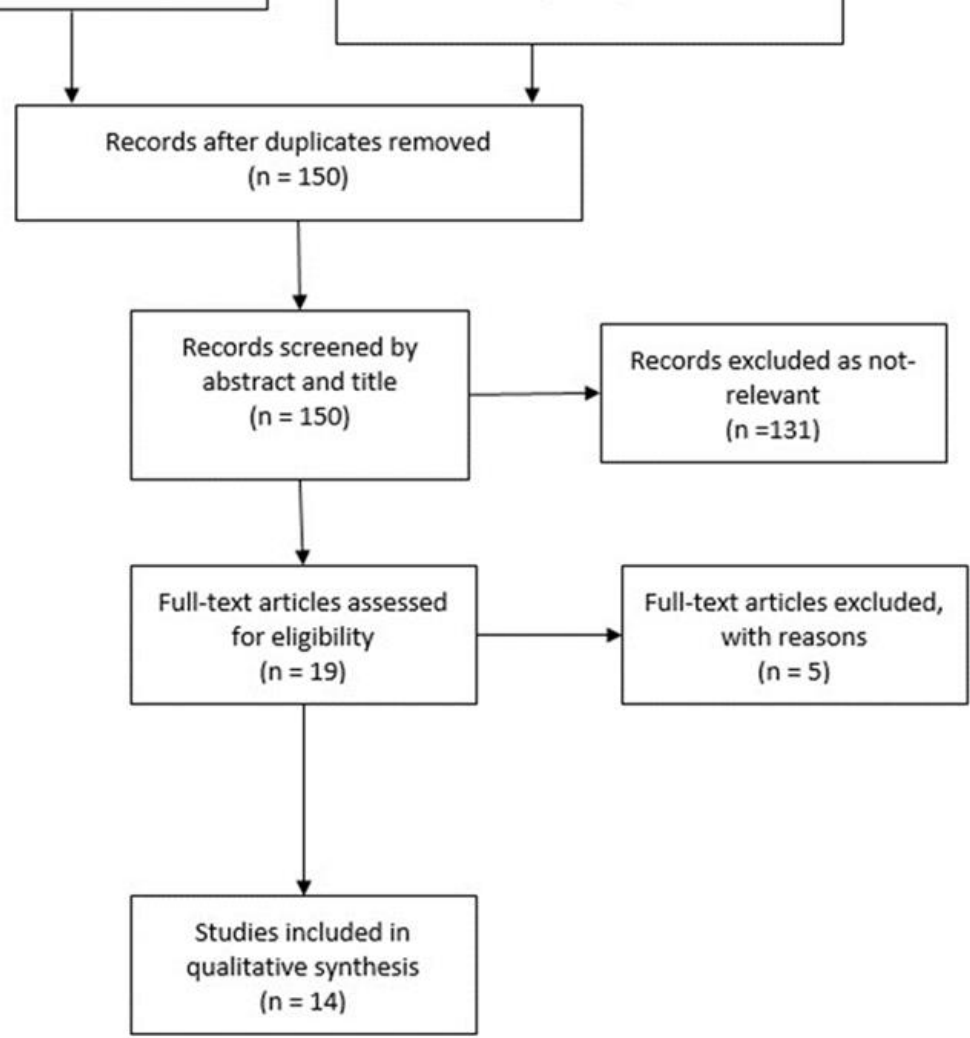


\section{Thematic synthesis of the results}

The synthesis of results identified nine themes for interventions: supportive leadership, introducing reporting system, analysing safety events and sharing the knowledge, staff education, development of patient safety and quality team, implementing evidence-based practices and standardized processes, hiring people fit to the culture, incorporating information technology, and implementing the five concepts of HRO (unspecified).

Six themes for measuring the outcomes were identified: safety culture, employee engagement, safety events and hospital acquired conditions, cost, number and duration of equipment failures, and patient experience. (Table 4)

In addition, three main themes for facilitators and five themes for barriers for a health care organization becoming a HRO were identified. The facilitators were: fewer safety events, less hospital acquired conditions, and cost avoidance. The barriers were: measuring wrong outcomes, choosing wrong interventions, different disciplines do not cooperate, financial barriers, and increased workload. (Table 4) The themes are discussed in detail below.

\section{Interventions}

The key factor, found in the literature, for successfully transforming to a HRO is support from the leaders. Leaders should be rolemodels and coaches for the staff. [26, 30, 33, 37] This requires education in specific methods to continuously reinforce error prevention behaviour and change management. [25, 33, 37] Many organizations demand their executives to have education in Lean/Six Sigma models. [33, 34, 36] All leaders should be engaged in structured safety rounds, implement routine safety huddles, and participate in organizational safety briefings. $[25,32]$ Leaders should work closely with the budgeting team for budgetary decisions to be in line with departmental and organisational quality and safety goals. [32, 33, 37] To assess the return on investment, business cases for each target variable should be developed. Ideally, the business case defines the problem and opportunity for each target variable, identifies root causes, and estimates costs and savings. [24]

Another necessary act is to implement an online reporting system for adverse outcomes, near misses, and risky situations. [24, 26-28, $32,33,37]$ Then, baseline on the selected outcome variables should be measured so that progress can be monitored, and resources appropriately deployed. [24, 25] After, a root cause analysis process should be implemented to identify and rectify causes of errors. [25-28, 31-34, 36, 37]

An important part is mandatory education for the staff and students. [28, 32, 37] The goals are to improve knowledge regarding human errors and to raise awareness of high-risk situations. [26, 30, 31, 33] Furthermore, separate training modules teamwork and communication skills are useful. [31, 34] Education is also required to implement certain safety behaviours such as standardized handoffs, safety checks, and peer- and selfchecking. [25-27, 30, 36] The tools and skills learned should be reinforced through constant practice, and regular feedback by safety coaches. $[25,27,30,31]$ 
Table 4. Thematic data synthesis.

\begin{tabular}{|c|c|c|}
\hline \multirow{2}{*}{\multicolumn{3}{|c|}{$\begin{array}{l}\text { Descriptive themes } \\
\text { INTERVENTIONS }\end{array}$}} \\
\hline & & \\
\hline \multirow[t]{4}{*}{ Supportive leadership } & Education of leaders & $24,25,30,32,34$ \\
\hline & Participating leaders & 25,32 \\
\hline & Role models and coaches & 26,30 \\
\hline & Budget reallocation & $24,30,33,35$ \\
\hline Introducing reporting system & & $24,26,27,28,31,32,33$ \\
\hline \multirow{8}{*}{$\begin{array}{l}\text { Analysing safety events and } \\
\text { sharing the knowledge }\end{array}$} & Sharing the results & $24,25,27,30,31,32,33,35$ \\
\hline & Root-cause analysis & $25,26,27,30,31,32,33,34,36$ \\
\hline & Observing and analysing risky situations & $28,31,34$ \\
\hline & Open disclosure & 35 \\
\hline & Direct feedback & 30 \\
\hline & Audits & 30 \\
\hline & Huddles & 25,30 \\
\hline & Peer review & 26,32 \\
\hline \multicolumn{2}{|c|}{ Staff education } & $24,25,26,27,28,30,31,32,34,36$ \\
\hline \multicolumn{2}{|c|}{ Development of patient safety and quality team } & 28,31 \\
\hline Implementing evidence-based & Check-lists & 26,36 \\
\hline practices and standardized & Identifying roles, practices and & 24 \\
\hline processes & Standardized processes & 32,36 \\
\hline & Evidence-based practices & 24 \\
\hline \multicolumn{2}{|l|}{ Hiring people fit to the culture } & 30,36 \\
\hline \multicolumn{2}{|c|}{ Incorporating information technology } & 30,36 \\
\hline \multicolumn{2}{|c|}{$\begin{array}{l}\text { Implementing five concepts of high reliability organization mindfulness } \\
\text { OUTCOME MEASURES }\end{array}$} & 29 \\
\hline Safety culture & & $26,27,28,31,32,33$ \\
\hline \multirow[t]{5}{*}{ Employee engagement } & Attendance to education & 26,33 \\
\hline & Documentation of the care plan & 36 \\
\hline & Accuracy in medication history collection & 36 \\
\hline & Number of failed nurse-supervisor & 29 \\
\hline & Improper notification of physician & 29 \\
\hline \multirow{10}{*}{$\begin{array}{l}\text { Safety events and hospital } \\
\text { acquired conditions }\end{array}$} & Organizational quality and safety objectives & $33,34,36$ \\
\hline & Patient harm index & 2528 \\
\hline & Adverse drug events & $24,27,28$ \\
\hline & Unnecessary blood transfusions & 30 \\
\hline & Length of intubation time & 30 \\
\hline & Asthma core measures & 27 \\
\hline & Hospital mortality & 28 \\
\hline & Number of patient discharged alive & 29 \\
\hline & Serious safety event & $24,26,27,28,31,32,33$ \\
\hline & Hospital acquired conditions & $24,27,28,30,34,35$ \\
\hline \multirow[t]{5}{*}{ Cost } & Per domain of harm & 28 \\
\hline & Per patient & 29 \\
\hline & Cost avoidance & 24,32 \\
\hline & Average bed occupancy & 29 \\
\hline & Patient length of stay & 29,36 \\
\hline \multicolumn{2}{|c|}{ Number and duration of equipment failures } & 29 \\
\hline \multicolumn{2}{|l|}{ Patient experience } & 29,34 \\
\hline \multicolumn{3}{|c|}{ FACILITATORS } \\
\hline \multirow{2}{*}{\multicolumn{2}{|c|}{$\begin{array}{l}\text { Fewer safety events } \\
\text { Less hospital acquired conditions }\end{array}$}} & $25,27,28$ \\
\hline & Less hospital acquired conditions & 24 \\
\hline \multicolumn{2}{|l|}{ Cost avoidance } & 24 \\
\hline & ARRIERS & \\
\hline \multicolumn{2}{|l|}{ Measuring wrong outcomes } & 26 \\
\hline \multicolumn{2}{|l|}{ Choosing wrong interventions } & 24 \\
\hline Different disciplines do not co- & & 34 \\
\hline Financial barriers & & $25,29,34$ \\
\hline Increased workload & & 33 \\
\hline
\end{tabular}




\section{Measuring the impact}

The review identified several things that can be measured to monitor the change. Each unit should choose the ones most suitable and descriptive. To track the overall process and encourage the staff to sustain the change, the improvement rate can be calculated by comparing the current quarter's or six months' rate to the baseline. [24, 37] Different safety events and hospital acquired conditions are the most used measurements. [24-35] Another common measure is change in safety culture. [26-28, 31-33] Staff engagement can be measured for example by measuring the education level of the staff. $[26,33]$

Facilitators for a health care organization becoming a HRO

The article by King et al. reports almost 16\% decrease in hospital-acquired conditions and approximately 13.5 million US dollar cost avoidance in two years. [24] Lyren et al. report $40 \%$ reduction in serious harm events in five years, [25] while Peterson et al. report 68\% reduction in serious safety events already after one year. [27] Hilliard et al. report $70 \%$ reduction in serious safety events after three years. [32] The article by Brilli et al. reports $85 \%$ decrease in the number of serious safety events per three months and they estimate that cost of preventable harm decreases $22 \%$ for calendar year in three years after implementing the new HRO strategy. [28]

Barriers for a health care organization becoming a HRO

The articles report several challenges to develop a HRO. An approach to developing a HRO that works in one unit might not work in another one even within the same organization. [24] It is important to choose carefully what to measure in each unit. For example, if serious safety events are rare, it takes a long time to prevent one event and thus, it takes long time to see the difference.
To keep the staff motivated it would be better to measure something that occurs more frequently such as hospital acquired conditions. [25] Each unit should be involved in determining how to implement processes and protocols in practice. [24] Chassin and Loeb have developed a framework with 14 components for the healthcare organizations toward a HRO status. [37] Organizations can use this model to check their current stage of maturity in four different levels and plan the next steps. [37]

Healthcare organizations are multidisciplinary teams and people should have knowledge of many different disciplines to effectively collaborate. Careful attention should be paid on training so that disciplines complement rather than compete. [34] After education, staff requires longitudinal learning opportunities that incorporate mentorship and coaching to effectively apply taught concepts and methods within their work environment. [33]

Time and cost are challenges to many organizations. Especially, because it takes more than a year to see benefits in cost. [29] Thus, it is important to align the HRO development targets with financial targets from the beginning. [24] Detection of the development targets and properly collecting the base values are the foundation of the HRO process. [24] However, it can be very timeconsuming. [25] Another situation where time is required is education. Time to attend education requires someone else doing the job of those away or work to be postponed. [33] Moreover, education itself costs and often, more staff must be hired to implement the new strategies. $[25,34]$

\section{DISCUSSION}

The findings of the systematic literature review of 14 articles suggest several interventions in 
all organizational levels for healthcare organizations to achieve HRO status. The most common types of interventions are Staff education, supportive leadership, creating a reporting system, and analysing the safety events and sharing the knowledge. [24-28, 3036] The main barriers for organizations are time, cost, and focusing on wrong methods and outcomes. [24, 25, 27, 28] Benefits come in reduction of serious safety events and cost avoidance. [24-26, 29, 33, 34]

Staff education is especially important in healthcare organizations because the high workforce turnover rate creates a demand for constant education and induction for new workers. [38] Supportive leadership decreases the turnover rate and increases employee engagement in change. $[39,40]$ The importance of supportive leadership can be seen in circumstances where there is a lack of support. Healthcare workers routinely observe unsafe conditions, behaviours, and practices, but often fail to bring those problems to information. [41] One reason is the intimidating behaviour healthcare workers are exposed when reporting safety problems. [42] In fact, the leading system-based cause for errors is a culture in which concerns are not reported because of the fear of intimidation. [27]

Another situation when support is required is after education of HRO principles, when the staff discovers that things are not as they seem and that there is much to learn. In units where there is not much problems with adverse events, the staff turnover rate and exhaustion can increase if the staff does not understand the reason for change. [43] However, in an environment where patient harm has been a recognized problem before, the safety process decreases exhaustion and staff turnover rate because now they have tools to solve the problems. [43]

Even though root cause analysis was used in several of the selected articles it should be implemented with caution. It is important to understand that reasons for errors can be very complex and using a simple root cause analysis might not detect them all. [44] Furthermore, root cause analysis is useless if risks detected are not properly eliminated and if the feedback loop does not work. [45] However, together with opportunity analysis, root cause analysis can demonstrate possible cost savings. [46]

Adverse events in healthcare are a huge problem worldwide, with medical errors being the 14th leading cause of morbidity and mortality in the world. [47] Moreover, it is estimated that $15 \%$ of the hospital expenditure in OECD countries is spent on treating medical errors. [48] To support healthcare leaders in making medical care safer, this systematic literature review answers to the demand for evidence-based recommendations for healthcare leaders on how to transform healthcare organization to a HRO. [49] The methods detected here are considered crucial in creating a safe healthcare environment. [50]

The literature review has some limitations. The quality of the selected papers was not high. Most of the articles included are case reports and case studies, and all are from the United States. Furthermore, most of the articles do not consider confounding factors possibly influencing the results. These factors can influence the reliability and generalisability of the results. Another limitation is that studies might have been excluded from the review due exclusion of articles not available online and published in other language than English. 
In conclusion, based on the evidence gathered in this analysis, and within the study limitations, the journey towards becoming a HRO is challenging but cost effective. It is important to educate the future leaders to create an atmosphere of trust where everyone with their skills and knowledge is appreciated and encouraged to question, ask, and report problems. To support an evidence-based journey towards HRO status in healthcare, future studies should focus in healthcare settings outside the United States and attention should be paid in study design, methods, and identification of confounding factors.

\section{References}

1. Australian Commission on Safety and Quality in Health Care. (2013). Literature Review: Medication Safety in Australia. Available: < https://safetyandquality.gov.au/wpcontent/uploads/2014/02/Literature-ReviewMedication-Safety-in-Australia-2013.pdf > (Accessed 18.10.2017)

2. Makary MA, Daniel M. Medical error-the third leading cause of death in the US. BMJ. 2016;353:i2139. 3. de Vries EN, Ramrattan MA, Smorenburg SM, Gouma DJ, Boermeester MA. The incidence and nature of inhospital adverse events: a systematic review. Qual Saf Health Care. 2008;17(3):216-23.

4. Hopkins A. Learning from high reliability organisations. Sydney: CCH Australia; 2009. p. 5-16. 5. Karl E. Weick KMS. Managing the unexpected: sustained performance in a complex world. 3rd ed. New York: John Wiley \& Sons Inc; 2015.

6. Weaver RR. Seeking high reliability in primary care: leadership, tools, and organization. Health Care Manage Rev. 2015;40(3):183-92.

7. Sutcliffe KM, Lewton $E$, Rosenthal MM. Communication failures: an insidious contributor to medical mishaps. Acad Med. 2004;79(2):186-94.

8. Reason JT. Managing the risks of organizational accidents. Abingdon: Routledge; 2016.

9. Fiol CM, O'Connor EJ. Waking up! Mindfulness in the face of bandwagons. Acad Manage Rev. 2003;28(1):5470.

10. Tucker AL, Singer SJ, Hayes JE, Falwell A. Front-line staff perspectives on opportunities for improving the safety and efficiency of hospital work systems. Health Serv Res. 2008;43(5p2):1807-29.

11. Hartmann CW, Meterko M, Rosen AK, Zhao S, Shokeen $\mathrm{P}$, Singer S, et al. Relationship of hospital organizational culture to patient safety climate in the Veterans Health Administration. Med Care Res Rev. 2009;66(3):320-38.
12. Dillon RL, Tinsley CH, Madsen PM, Rogers EW. Organizational correctives for improving recognition of near-miss events. J Manage. 2016;42(3):671-97.

13. van der Vegt GS, Essens P, Wahlström M, George G. Managing risk and resilience. Acad Manage J.

2015;58(4):971-80.

14. van Dyck C, Frese M, Baer M, Sonnentag S.

Organizational error management culture and its impact on performance: a two-study replication. J Appl Psychol. 2005;90(6):1228-40.

15. Boin A, van Eeten MJG. The resilient organization. Public Manag Rev. 2013;15(3):429-45.

16. Christianson MK, Sutcliffe KM, Miller MA, Iwashyna TJ. Becoming a high reliability organization. Crit Care. 2011;15(6):314.

17. Padgett J, Gossett K, Mayer R, Chien W-W, Turner F. Improving patient safety through high reliability organizations. Qual Rep. 2017;22(2):410-25.

18. Klein KJ, Ziegert JC, Knight AP, Xiao Y. Dynamic delegation: Hierarchical, shared and deindividualized leadership in extreme action teams. Adm Sci Q. 2006;51(4):590-621.

19. Cawley PJ, Scheurer DB. Achieving high reliability through cultural mindfulness. Front Health Serv Manage. 2017;33(4):3-15.

20. Moher D, Liberati A, Tetzlaff J, Altman DG. Preferred reporting items for systematic reviews and metaanalyses: the PRISMA statement. PLoS Med. 2009;6(7):e1000097.

21. Methley AM, Campbell S, Chew-Graham C, McNally R, Cheraghi-Sohi S. PICO, PICOS and SPIDER: a comparison study of specificity and sensitivity in three search tools for qualitative systematic reviews. BMC Health Serv Res. 2014;14:579.

22. CASP, Critical, appraisal, skills, programme. CASP

Cohort Study Checklist 2017 Available: <

http://docs.wixstatic.com/ugd/dded87_5ad0ece77a3f4f c9bcd3665a7d1fa91f.pdf > (Accessed 21/11/2017) 
23. Thomas J, Harden A. Methods for the thematic synthesis of qualitative research in systematic reviews. BMC Med Res Methodol. 2008;8:45.

24. King HB, Kesling K, Birk C, Walker T, Taylor H, Datena $M$, et al. Leveraging the partnership for patients' initiative to improve patient safety and quality within the Military Health System. Mil Med.

2017;182(3):e1612-e9.

25. Lyren A, Brilli R, Bird M, Lashutka N, Muething S. Ohio Children's Hospitals' Solutions for Patient Safety: A Framework for pediatric patient safety improvement. J Healthc Qual. 2016;38(4):213-22.

26. Woodhouse KD, Volz E, Bellerive M, Bergendahl HW, Gabriel PE, Maity A, et al. The implementation and assessment of a quality and safety culture education program in a large radiation oncology department. Pract Radiat Oncol. 2016;6(4):e127-34.

27. Peterson TH, Teman SF, Connors RH. A safety culture transformation: Its effects at a children's hospital. J Patient Saf. 2012;8(3):125-30.

28. Brilli RJ, McClead RE, Crandall WV, Stoverock L, Berry JC, Wheeler TA, et al. A comprehensive patient safety program can significantly reduce preventable harm, associated costs, and hospital mortality. J Pediatr. 2013;163(6):1638-45.

29. Hales DN, Kroes J, Chen Y, Kang KW. The cost of mindfulness: A case study. J Bus Res. 2012;65(4):570-8. 30. Lyman B, Ethington KM, King C, Jacobs JD, Lundeen $\mathrm{H}$. Organizational learning in a cardiac intensive care unit: a learning history. Dimens Crit Care Nurs. 2017;36(2):78-86.

31. Muething SE, Goudie A, Schoettker PJ, Donnelly LF, Goodfriend MA, Bracke TM, et al. Quality improvement initiative to reduce serious safety events and improve patient safety culture. Pediatrics. 2012;130(2):e423-31. 32. Hilliard MA, Sczudlo R, Scafidi L, Cady R, Villard A, Shah R. Our journey to zero: reducing serious safety events by over $70 \%$ through high-reliability techniques and workforce engagement. J Healthc Risk Manag. 2012;32(2):4-18.

33. Aboumatar HJ, Weaver SJ, Rees D, Rosen MA, Sawyer MD, Pronovost PJ. Towards high-reliability organising in healthcare: a strategy for building organisational capacity. BMJ Qual Saf. 2017;26:663-70. 34. Pronovost PJ, Holzmueller CG, Molello NE, Paine L, Winner L, Marsteller JA, et al. The Armstrong Institute: an academic institute for patient safety and quality improvement, research, training, and practice. Acad Med. 2015;90(10):1331-9.

35. Hendrich A, Haydar Z. Building a high-reliability organization: one system's patient safety journey. J Healthc Manag. 2017;62(1):13-7.

36. Saunders $\mathrm{CL}$, Brennan JA. Achieving high reliability with people, processes, and technology. Front Health Serv Manage. 2017;33(4):16-25.

37. Chassin MR, Loeb JM. High-reliability health care: getting there from here. Milbank Q. 2013;91(3):459-90. 38. Hines S, Luna K, Lofthus J, al. e. Becoming a high reliability organization: operational advice for hospital leaders. Rockville, MD: Agency for Healthcare Research and Quality; 2008. Available: < https://archive.ahrq.gov/professionals/quality-patientsafety/quality-resources/tools/hroadvice/hroadvice.pdf $>$ (Accessed 25/10/2017)

39. Yanchus NJ, Periard D, Osatuke K. Further examination of predictors of turnover intention among mental health professionals. J Psychiatr Ment Health Nurs. 2017;24(1):41-56.

40. Cochrane BS, Hagins M, Jr., Picciano G, King JA, Marshall DA, Nelson B, et al. High reliability in healthcare: creating the culture and mindset for patient safety. Healthc Manage Forum. 2017;30(2):61-8. 41. Hamilton EC, Pham DH, Minzenmayer AN, Austin $\mathrm{MT}$, Lally KP, Tsao K, et al. Are we missing the near misses in the OR?-underreporting of safety incidents in pediatric surgery. J Surg Res. 2018;221:336-42.

42. Derickson R, Fishman J, Osatuke K, Teclaw R, Ramsel D. Psychological safety and error reporting within Veterans Health Administration Hospitals. J Patient Saf. 2015;11(1):60-6.

43. Vogus TJ, Cooil B, Sitterding M, Everett LQ. Safety organizing, emotional exhaustion, and turnover in hospital nursing units. Med Care. 2014;52(10):870-6. 44. Wu AW, Lipshutz AM, Pronovost PJ. Effectiveness and efficiency of root cause analysis in medicine. JAMA. 2008;299(6):685-7.

45. Peerally MF, Carr S, Waring J, Dixon-Woods M. The problem with root cause analysis. BMJ Qual Saf. 2017;26:417-22.

46. Latino RJ. How is the effectiveness of root cause analysis measured in healthcare? J Healthc Risk Manag. 2015;35(2):21-30.

47. Jha AK, Larizgoitia I, Audera-Lopez C, Prasopa-Plaizier $\mathrm{N}$, Waters $\mathrm{H}$, Bates DW. The global burden of unsafe medical care: analytic modelling of observational studies. BMJ Qual Saf. 2013;22(10):809-15.

48. Slawomirski L., Auraaen A., Klazinga N. The cost of failure. 2017. In: The economics of patient safety: strengthening a value-based approach to reducing patient harm at national level. OECD Health Division. Available: < https://www.oecd.org/els/healthsystems/The-economics-of-patient-safety-March2017.pdf > (Accessed 27/01/2018)

49. Tolk JN, Cantu J, Beruvides M. High reliability organization research: a literature review for health care. Engineering Management Journal. 2015;27(4):21837.

50. Stone P.W., Hughes R., Dailey M. Creating a safe and high-quality health care environment. 2008. In: Patient safety and quality: an evidence-based handbook for nurses. Rockville: Agency for Healthcare Research and Quality. Available: < https://www.ncbi.nlm.nih.gov/books/NBK2634/ > (Accessed 27/01/2018) 
Table 3. Quality assessment of included studies a.

\begin{tabular}{|c|c|c|c|c|c|c|c|c|c|c|}
\hline Study & $\begin{array}{l}\text { Clear } \\
\text { focus }\end{array}$ & $\begin{array}{l}\text { Representative } \\
\text { population }\end{array}$ & $\begin{array}{l}\text { Exposure } \\
\text { accurately } \\
\text { measured to } \\
\text { minimise bias }\end{array}$ & $\begin{array}{l}\text { Outcomes } \\
\text { accurately } \\
\text { measured to } \\
\text { minimise bias }\end{array}$ & $\begin{array}{l}\text { Important } \\
\text { confounding } \\
\text { factors identified }\end{array}$ & $\begin{array}{l}\text { Confounding } \\
\text { factors } \\
\text { considered in } \\
\text { design and/or } \\
\text { analysis } \\
\end{array}$ & $\begin{array}{l}\text { Complete } \\
\text { enough } \\
\text { follow-up }\end{array}$ & $\begin{array}{l}\text { Preciseness of } \\
\text { the results }\end{array}$ & Reliability & Generalisability \\
\hline $\begin{array}{l}\text { Aboumatar et } \\
\text { al., } 2017\end{array}$ & + & + & - & - & - & - & + & - & - & + \\
\hline $\begin{array}{l}\text { Brilli et al., } \\
2013\end{array}$ & + & + & + & + & - & - & + & + & + & + \\
\hline $\begin{array}{l}\text { Chassin \& } \\
\text { Loeb, 2013 }\end{array}$ & + & - & - & - & - & - & $\mathrm{n} / \mathrm{a}$ & $\mathrm{n} / \mathrm{a}$ & $\mathrm{n} / \mathrm{a}$ & + \\
\hline $\begin{array}{l}\text { Hales et al., } \\
2012\end{array}$ & + & + & + & $\mathrm{n} / \mathrm{a}$ & + & - & + & + & + & + \\
\hline $\begin{array}{l}\text { Hendrich \& } \\
\text { Haydar, 2017 }\end{array}$ & + & + & - & - & - & - & + & - & - & + \\
\hline $\begin{array}{l}\text { Hilliard et al. } \\
2012\end{array}$ & + & + & + & + & + & - & + & + & + & + \\
\hline $\begin{array}{l}\text { King et al., } \\
2017\end{array}$ & + & + & + & + & - & - & + & + & + & + \\
\hline $\begin{array}{l}\text { Lyman et al., } \\
2017\end{array}$ & + & + & + & + & - & - & + & + & + & + \\
\hline $\begin{array}{l}\text { Lyren et al., } \\
2016\end{array}$ & + & + & - & + & - & - & + & + & + & + \\
\hline $\begin{array}{l}\text { Muething et } \\
\text { al., } 2012\end{array}$ & + & + & + & + & - & - & + & + & + & + \\
\hline $\begin{array}{l}\text { Peterson et } \\
\text { al., } 2012\end{array}$ & + & + & + & + & - & - & + & + & + & + \\
\hline $\begin{array}{l}\text { Pronovost et } \\
\text { al., 2015 }\end{array}$ & + & + & - & - & - & - & + & - & - & + \\
\hline $\begin{array}{l}\text { Saunders \& } \\
\text { Brennan, 2017 }\end{array}$ & + & + & - & - & - & - & + & - & - & + \\
\hline $\begin{array}{l}\text { Woodhouse et } \\
\text { al., } 2016\end{array}$ & + & + & + & + & - & - & + & + & + & + \\
\hline
\end{tabular}

${ }^{a}$ Modified from CASP cohort study check list (CASP, Critical appraisal skills programme, 2017) 